\title{
Children Webbed in the Cyber Network: an Exploratory Study on Children's Cyber Behavior and Cyber Laws
}

\author{
Nouzia Noordeen ${ }^{1}$, Dr. C. Jayan ${ }^{2}$
}

\section{ABSTRACT}

With the IT Revolution, Cyber world has become a part of kid's natural environment. Though the computer and the internet provide fantastic opportunities for socially beneficial endeavorssuch as education, research, commerce and entertainment, at the same time they serve as tools to facilitate illegal activity. Often children see their own ability to defeat technological limitations and controls as a way to show up their parents and teachers, or as a badge of honor and subject to brag about among their friends both offline and online. Legal issues pertaining to the need to protect children and youth online are now being considered to a larger extend since the hidden risk raise a potential threat to the well being of young generation. There is also the risk that a child could engage in some negative legal or financial consequences or committing a cybercrime. The present study is focused on explaining cyber behavior of children and also exploring various cyber laws to protect the rights of children online. The data was collected using interview and self-report method. The qualitative research design was employed to analyze the data. The study reflected a greater need for children's online protection, stressed on the problems children encounter in the cyber world as well as provided insight into the prevailing cyber laws.

Keywords: Cyber world, Cyber behavior, Legal rights, Cyber laws.

Crime in a virtual world can take a number of forms. Some activities such as the theft of goods are relatively clear-cut whereas private law issues such as harassment or commercial disputes are more complex. The Internet has made certain kinds of criminal activities much more attractive, since cyberspace possesses unique characteristics that may actually encourage the commission of criminal acts. Crimes committed in connection with the Internet (commonly called "cyber crimes") have attracted widespread attention. Cybercrime encompasses an enormous range of offenses, from hacking to online fraud to child pornography. Research now reveals that adolescents often learn from friends or family members how to steal such intellectual property using peer-to-peer networks on the Internet. In the process they associate this behavior as being

${ }^{1}$ P.hD Scholar, Department of Psychology, University of Calicut, Thenjhipalam, Malappuram district, Kerala, India

${ }^{2}$ Professor, Head of the Department, Department of Psychology, University of Calicut, Thenjhipalam, Malappuram district, Kerala, India

(C) 2015 I N Noordeen, C Jayan; licensee IJIP. This is an Open Access Research distributed under the terms of the Creative Commons Attribution License (http://creativecommons.org/licenses/by/2.0), which permits unrestricted use, distribution, and reproduction in any Medium, provided the original work is properly cited. 


\section{Children Webbed in the Cyber Network: an Exploratory Study on Children's Cyber Behavior and Cyber Laws}

normal and with being accepted socially. With more and more computers interconnected via the Internet, more abuses of computer systems drove state governments and the central government to begin passing computer crime laws. Initially these laws focused on the growing phenomenon of computer hacking, but were soon expanded into other types of criminal behaviors. In effect, computerization made possible by inventions and innovations in computing and telecommunications technologies also made possible, if not inevitable, the concept of "computer crime." This concept, however, became outdated as computer technologies became smaller, more powerful, more affordable, and capable of performing many tasks including uploading and downloading data files on the Internet. With the emergence of the World Wide Web in 1993, along with a myriad of software applications, online content, and the beginning of high speed/broadband Internet connections, computer crime evolved into computer-related crime and then what we know today as cybercrime. Much cybercrime is committed for much the same motives and by much the same people as have always been tempted to criminal activity, although there are some exceptions. Many of the differences relate to the opportunity, access, impact, and range of activities that can be engaged in, although factors such as the anonymity and disinhibition that the Internet affords are also important psychological differences.

Children and teens flock to the environment in which anonymity and brevity of e-mail communications provide safe cover for avoiding the detection of online contact by parents, system monitors, and law enforcement agents (Murphy, 1995). The internet seems to provide an easier route for child predators to encounter and engage with children and teenagers. Two of the most personal forms of online attack are cyber bullying and cyber stalking. While this activity is not always considered criminal, some jurisdictions treat cyber bullying acts as offences. This is especially the case when they include direct threats or physical assault. Cyber stalking may also be included in the stalking laws of many jurisdictions.

Cybercrime is a social problem as well as a legal one. The law enforcement world is scrambling to catch up, the legislators are passing new laws to address this new way of committing crime, and the police agencies are forming special computer crime units and pushing their officers to become more technically savvy. However, the cybercrime problem is too big and too widespread to leave to politicians and police to solve. As more individuals own and operate Internet enabled devices, and more critical governmental and industrial systems rely on advanced technologies, the issue of cybercrime has become a crucial concern for both the general public and professional's alike. Computer technologies have continually and rapidly changed and advanced in the last two decades. The impacts of these rapid changes are affecting the use and applications of computer technologies in society. These impacts bring about new focus and new scrutiny. One of the fundamental changes in the last decade has been the realization that the context in which computer technologies are used must take into account the ethical implications associated with its use. The difference in advancement offers fertile ground to illegal trades, unethical behaviors, and unmonitored activities in general. Such observation is true for any new endeavor, but it is 


\section{Children Webbed in the Cyber Network: an Exploratory Study on Children's Cyber Behavior and Cyber Laws}

exacerbated by the high levels of diffusion among the peoples of the world, blurring national boundaries or cultural habits. As the world heads towards a technological global harmonization, the legal systems especially, but also the frames of reference that the field of ethics offers seem to diverge rather than converge. As new technologies continue to evolve, so too must our understanding of its ethical and legal implications. When a new tool or technology is invented and introduced, what emerges is not always what was originally intended. These new emerging ideas and other advances can have long lasting influences that cannot always be readily foreseeable. Cyber law and cyber ethics are important domains whose understanding is instrumental to understand our future as a society as our lives become ever further meshed and integrated with the ever growing connected digital world.

Theories of crime are an important part of criminological literature. Different theories address the issue of crime at various levels, ranging from societal, through community and socialization influence theories, to the most specific level, individual theories. The aim of most of the theories of crime is to explain why crime occurs and who is most likely to engage in criminal acts, and as such they are an important element of developing a thorough understanding of the psychology of cybercrime. Many of the high level theories of crime are mainly sociological, geographical or political in scope, whereas theories of crime that consider socialization and individual differences are those which are most suited to psychological discussion. While it must be remembered that there has been little empirical examination of how these theories specifically relate to cybercrime, some theories show potential for explaining the nature of the phenomenon. While some of the theories, models and research in conventional psychology can be directly applied to cyber psychology, this is not always the case, and as such this provides a basis for the argument that cyber psychology could be considered to be a qualitatively new area within psychology (Kirwan, 2010).

The nature of the response is multi-faceted. Governments attempt to respond with law, corporations with policies and procedures, suppliers with terms and conditions, users with peer pressure, technologists with code. The international laws have evolved through what are referred to a 'soft law' and seeks to draw lessons for the evolution of laws for the internet. The question of how ideas of governance have evolved and how some of the theoretical work in this field may offer guidance for the governance of the internet is also considered. Governments are also losing influence with their citizens as power is lost to interest groups, influential individuals and media organizations. Citizens are disengaging with the political process as they perceive their ability to effect change is diminishing. As individuals spend more time online, form relationships and interest groups in virtual worlds, threats and traps are becoming uncontrollable, hence marking the need for cyber laws. 


\section{METHOD}

\section{Objective}

- To explore the various cyber behavior of children.

- To discuss the cyber laws especially pertaining to the children.

\section{Participants}

The sample consists of 120 students, both boys and girls, from classes 8 to plus one,of different age group ranging between 11-14 years.

\section{Measures}

Interview technique and self-reports were used to collect data for the present study.

\section{Procedure}

In order to interact with the students, formal permission was sought from the head of the institution. Once permission was granted classes were allotted by the concerned teacher-incharge. The purpose of the study was told in brief and rapport was established with the students. The students were given blank sheets and requested to write their opinions and views regarding various uses and misuses of internet and mobile phones in their daily lives. They were also enquired about incidents that had occurred to them, friends or relatives while using internet or mobile phones. They were asked to quote down if they had come across any such incidents. Few questions were raised pertaining to their knowledge in the existing cyber laws. Responses were collected which was later content analyzed.

\section{ANALYSIS AND DISCUSSION}

From the analysis of the data it was clear almost all children have exposure to the internet and mobile phones. Majority of the children possess their own mobile phones and some children reported that they use their parents or elder sibling's mobile phones and internet for various purposes. Children, in general use these facilities from an early age itself, so they are quite aware of its uses. The study revealed high dependence of school children on internet and mobile phones.

In the school setting, children use internet and mobile phones for different academic purposes. According to them, these facilities are of a greater help in their projects and assignments. When teachers provided them with topics of assignment they seek majority of information from internet rather than from related books. Some students reported that they get ample information on their subjects from internet compared to class lectures. Students even shared notes and other classroom-related news through mobile phones or internet. In order to get a wider perspective and different ideas internet has lot to provide. They depend on internet to download previous 


\section{Children Webbed in the Cyber Network: an Exploratory Study on Children's Cyber Behavior and Cyber Laws}

years question papers, notes on their project, that all add value to their performance at school. Thus, parents as well as teachers support children in their perspective as they very well agree the amount of information that could be provided to the children in the classroom by them are limited and confined to the syllabus and curricula. So the only way of gaining such vast information regarding the topic of study or interest is to find them from books. If available books are limited, children will automatically depend on internet as it is an easiest and fastest medium to have access and the details will be at the fingertip in no time.

Apart from the advantages that one could impart from internet there are many hidden hazards to this fastest means of communication networking system. Internet has its demerits if one doesn't use it properly that too without accurate assistance. There are many false information and websites that provide fake details regarding various topics. Children do use internet to copy the same information given in the article and submit without adding their own points or ideas. Plagiarism can be widely seen in the academic setting as children directly copy-paste their subjects. They do not find time to read and understand but just copy and paste it as it is given in the websites. They become lazy in finding knowledge and do not spend time to gain required information. Without understanding the topic, they blindly copy articles that are posted by someone else. They might not be even authentic articles. Information may be false. Not considering these, children fall prey to this custom of blindly copying all that information given on the internet. Their creativity and thinking process are no longer utilizing in producing an assignment of given topic as they simply write down what is on the web page and submitting it before the last date to get enough marks which has now become their ultimate aim in doing assignments. Another finding from the study was that though mobile phones are highly restricted in the school compounds, there were students who bring mobile phones to the classrooms and cheated in the examination hall.

Internet has become an easier means for students to get a great deal of information. Data revealed that children used internet not only for study purposes but also for entertainment. They reported that they were also involved in downloading movies, music, games and enjoy having fun in using internet and mobile phones. From the study it was found that once children started using it out of curiosity slowly they become glued to it. Many disclosed that they spent many hours on mobile phone and internet browsing rather than studying and being with family. This pointed to the growth of a new generation that gets contented in browsing alone in near future. They found internet and mobile phones very fascinating and thus absorbed in experimenting it in order to gain experiences that jeopardized them.

Many studies reported that each year thousands of adolescents and adults are bullied, threatened, harassed, and/ or stalked online. People using computers and other types of information technology (IT) devices such as mobile phones access and use the internet, to voluntarily or unintentionally post personal information about themselves to social computing forums, web sites, blogs, and chat rooms; and unscrupulous and/or illegal behaviors of cyber offenders who 


\section{Children Webbed in the Cyber Network: an Exploratory Study on Children's Cyber Behavior and Cyber Laws}

intentionally use the same technology and internet resources to harm people in these ways. When children or youth are involved, this problem is often considered "cyber bullying". In reality anyone can be bullied, threatened, or harassed online, and some people are also stalked online as well as in person or both. Online harassment may involve offensive or insulting messages repeatedly sent electronically to a victim. This can also involve sending or posting denigrating or inaccurate information about a victim to others with the intent to disrupt friendships or damage their reputation. Among children and adolescents this is done by posting information incurring disrespect or revenge from their friends or associates. Often harassment that is initiated in the cyber world transcends into classrooms and educational settings, or social functions and leads to physical harm to victims.

Children believed in the cyber world's false sense of privacy and security and tend to share all confidential information regarding them. Through online chatting, texting and video conferencing some children blindly trusted the strangers and fell prey to fraudulent activities. The data showed greater number of children was cheated on online love affairs. Some later regretted whereas some continued to repeat the same mistakes. Once they started to experience virtual love and develop friendship, they become too much obsessed with it. The consequences are ignored in the beginning but the reality hits in no time. When they really understand that they were taken advantage of and got cheated, it would be too late. Some children reported suicide attempts. Others displayed disappointment, stress, frustration, helpless and loneliness condition. This revealed that many online experiences lead these budding youngsters to give away their lives where exactly this is their most enjoyable and intellectual period of life.

It was also found internet addiction and viewing sexually implicit materials among children are increasing to a larger extent. The severity of addiction is determined by its impact on various areas of an individual's life, including heath, studies, and relationships with family, friends, and society. When they were enquired about the amount of time they spent each day on internet and browsing they came up with different responses. But still their responses reflected an increased amount of hours spent on chatting, texting and gaming. There were some who could not even think about not having internet and mobile phones which showed how much addicted they are. Some children reported that they view pornography and sexually implicit images on internet and mobile phones. Some responded that their friends view such sexual materials online and now they could not resist from viewing it now. This has reduced interest in their studies and other recreations. There were few who genuinely wish to adopt different measures to overcome this addiction but they are quite unknown about it and helpless.

Another important finding was the lack of parental supervision. According to children, parents are unaware of internet, its technicalities, advantages and consequences. But when children insisted on buying computer, mobile phones and internet connection, parents provided them such facilities and their role was over there. There will be some who commit cybercrime unknown 


\section{Children Webbed in the Cyber Network: an Exploratory Study on Children's Cyber Behavior and Cyber Laws}

about its consequences. Almost all of the students are not telling their parents when they see something objectionable on the internet. When parents do not guide their children, their offsprings will not come to know what is right and what is wrong on internet. They continue experimenting and end up in trouble. When even parents are ignorant about it there will be no other source for them to seek right path instead share the same with friends and repeat or continue it. Eventually children intentionally or unintentionally will become cyber victims.

Children's risky behavior can be explained well with a victimization theory. The Routine activities theory (Cohen \& Felson, 1979) hypothesizes that the volume and distribution of cybercrime are closely related to the interaction of three variables that reflect the routine activities of children's typical lifestyle. The availability of suitable targets, the absence of capable guardians and the presence of motivated offenders- the presence of each of these components increases the likelihood that a cybercrime will take place. Children at their age do not think of various consequences that have to be faced while performing various actions on internet and mobile phones. Their innocence is taken advantage by those pedophiles and other cyber offenders, thus leading to children becoming cyber victims. When parental supervision is not there, children can become highly vulnerable to the cyber victimization. The analysis of data revealed children at home and school use internet and mobile phones devoid of observation by elders. Many have reported watching pornography and sending inappropriate texts to friends. There were some who shared their experience of strangers sending vulgar texts and e-mails. They fear revealing it to their parents or teachers. They do not report these experiences either out of fear or shame but live with burdened heart. All these can finally contribute to children committing suicide to escape from these threats and unbearable stress as well as from several problems that they have involved with. The unique attributes which make cyberspace an attractive forum for expression also create an environment well-suited to criminal activity because police detection of criminals and prevention of crimes is difficult. The anonymity of online users and their ability to role-play (assuming whatever role the user chooses) are freedoms which clearly do not exist in face-to-face interactions (Gregg, 1996). Hence cyber world provides them with every opportunity to attack an innocent kid online. The presence of motivated offenders cannot be completely prevented from the cyber world though many legislative measures and online protection acts have evolved. The theory can be implemented and its hypotheses are supporting the present study.

Various statutory provisions of cybercrimes are neglected. The world 1st computer specific law was enacted in the year 1970 by the German State of Hesse in the form of 'Data Protection Act, 1970' with the advancement of cyber technology. Indian parliament passed its "INFORMATION TECHNOLOGY ACT, 2000 to deal with the technology in the field of e-commerce, egovernance, e-banking as well as penalties and punishments in the field of cyber crimes.The Information Technology Act deals with the various cyber crimes in chapters IX \& XI. The important sections are Ss. 43,65,66,67. Section 43 deals with unauthorised access, unauthorised 


\section{Children Webbed in the Cyber Network: an Exploratory Study on Children's Cyber Behavior and Cyber Laws}

downloading, virus attacks or any contaminant, causes damage, disruption, denial of access, interference with the service availed by a person. This section provide for a fine up to Rs. 1 Crore by way of remedy. Section 65-'tampering with computer source documents' and provides for imprisonment up to 3 years or fine, which may extend up to 2 years or both. Section 66'hacking with computer system' and provides for imprisonment up to 3 years or fine, which may extend up to 2 years or both. Section 67- publication of obscene material and provides for imprisonment up to a term of 10 years and also with fine up to Rs. 2 lakhs. The Indian Penal Code, 1860 contains provisions to deal with the menace of cyber defamation. It includes Section 499 of IPC, Section 569 of IPC and Section 503 of IPC. Other cyber laws are The child internet Protection Act (CIPA) 2001, The Prosecution Remedies \& Other Tools to End the Exploitation of Children Today Act (PROTECT) of 2003 and Controlling the assault of Non-solicited Pornography \& Marketing Act (CAN-SPAM) of 2003 (Mc Qu ade, S .C , 2006).

\section{CONCLUSIONS}

The constant development of new technologies such as the internet, mobile phones and other digital communication devices are increasingly becoming a modern day must have for children. While it is acknowledged that the Internet has tremendous benefits and continues to enrich society in general, provides abundance knowledge and facilitates interpersonal communication and interaction, a darker side exists too. The internet is largely uncensored. The easy accessibility of the internet via the home, schools, public libraries, Internet cafes and 3G mobile phones, children are exposed not only to readily available inappropriate material but also unsolicited communication by strangers. Lack of guidance and guardian supervision and the excitement and curiosity to experiment novelty coupled with total ignorance in the risks that follows can make a child prone to cyber world's boundless menaces.

Since users of computer system and internet are increasing worldwide, where it is easy to access any information easily within a few seconds by using internet which is the medium for huge information and a large base of communications around the world, certain precautionary measures should be taken by netizens while using the internet which will assist in challenging this major threat Cyber Crime.

\section{REFERENCES}

Alexander, J. (2002). Homo-pages and queer sites: Studying the construction and representation of queer identities on the world wide web. International Journal of Sexuality and Gender Studies, 7(2/3), 85-106.

Bargh, J.A. (2002). Beyond simple truths: The human-Internet interaction. Journal of Social Issues, 58, 1-8.

Cohen,L, \&Felson,M. (1979). Social Change and Crime Rate Trends: A Routine Activities Approach. American Sociological Review, 44, 588-608 


\section{Children Webbed in the Cyber Network: an Exploratory Study on Children's \\ Cyber Behavior and Cyber Laws}

Drucker,S.J. \& Grumpert,G. (2000). Cyber Crime and punishment. Critical Studies in Media Communication, 17:2, 133-158

Fluri, J.L. (2006). 'Our website was revolutionary': Virtual spaces of representation and resistance. ACME: An International E-Journal for Critical Geographies, 5, 89-111. Retrieved from www.acme-journal.org/vol5/Fluri.pdf

Gregg, J. (1996). Caught in the web: Entrapment in cyberspace.Hastings Communication/ Entertainment Law Journal, 19, 157-197.

Kirwan, G. (2010). Cyberpsychology: An overview of emerging research in emerging environments. The Irish Journal of Psychology, 31, 157-172.

Livingstone, S. (2003). Children's use of the Internet: Reflections on the emerging research agenda. New Media \& Society, 5, 147-166

McQuade,S.C. (2006). Cyberlaws and regulations. In Understanding and managing cybercrime, Boston: Allyn and Bacon.

Mehra, B., Merkel, C., \& Bishop, A.P. (2004). The Internet for empowerment of minority and marginalized users. New Media \& Society, 6, 781-802.

Murphy, K. (1995, June 11). Youngsters falling prey to seducers in computer crime web: Once candy was the lure, now strangers are using cyberspace e-mail to attract minors into harm's way.L.A. Times, 1.

Siegel,L.J. (2007). Criminology: Theories, Patterns, and typologies. ( $\left.9^{\text {th }} \mathrm{ed}\right)$. USA: Thomson Wadsworth.

Snakenborg.J., Acker,R.V.,\&Gable,R.A.(2011).Prevention and Intervention to Protect our Children and Youth.Cyber Bullying, 55:2, 88-95. 